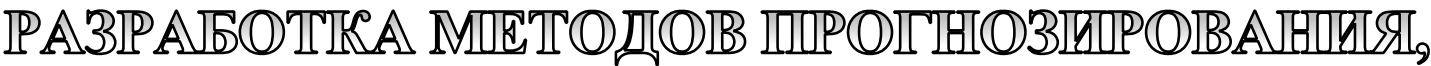

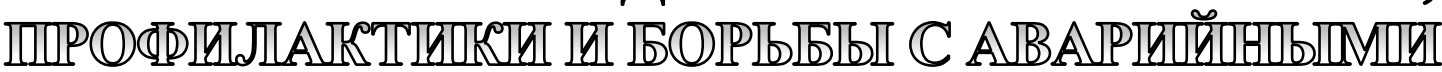

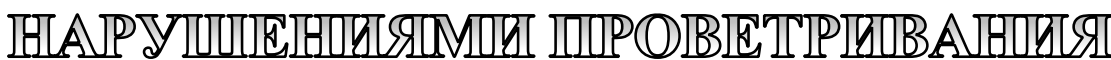

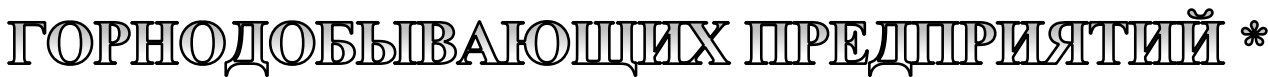

\author{
Б.П. Казаков, Горный институт УрО РАН \\ А.В. Шалимов, Горный институт УрО РАН \\ Е.Л. Гришин, Горный институт УрО РАН \\ А.В. Зайцев, Горный институт УрО РАН \\ А.Г. Исаевич, Горный институт УрО РАН \\ Д.С. Кормщиков, Горный институт УрО РАН
}

Исследования аэро- и теплогазодинамических процессов, протекающих в аварийных режимах проветривания, в частности во время рудничных пожаров, являются основой для разработки комплекса мероприятий, направленных на предотвращение возникновения аварий, а также на управление аварийным проветриванием в реальном времени. Описание процессов переноса тепла и дыма по горным выработкам проведено на основе тепломеханического расчёта, в основу которого положена математическая модель сопряжённого нестационарного теплообмена. Моделирование нестационарного воздухораспределения под действием переменных тепловых депрессий осуществлено на базе модифицированного метода контурных расходов, учитывающего инерционность воздушных потоков и механическую сжимаемость воздуха в выработанных пространствах рудника. Для оценки устойчивости аварийного проветривания рудника в случае отключения источника тяги разработана модель конвективного расслоения воздушных потоков по сечению горных выработок. На основании законов сохранения энергии и импульса выведены универсальные математические зависимости для определения потерь депрессии на сопряжениях горных выработок произвольной конфигурации, с помощью которых проведены исследования реверсивных режимов проветривания.

Проведён анализ эфффективности проветривания рабочих зон рудников с выработками большого сечения за счет использования рециркуляционных систем с эжектирующими источниками тяги. Разработан способ интерактивной работы с данными при подготовке и обработке результатов воздушно депрессионных съёмок вентиляционных сетей рудников, позволяющий определять аэродинамические сопротивления всех выработок в условиях недостающих или избыточных противоречивых данных. На основе

* Статья подготовлена при финансовой поддержке гранта РФФИ, проект № 17-45-590973 «Разработка методов прогнозирования, профилактики и борьбы с аварийными нарушениями проветривания горнодобывающих предприятий». 
комплексного учёта аэрологических и теплофизических фракторов, определяющих параметры рудничной атмосферы, разработана система управления воздушными потоками в аварийных режимах проветривания с помощью регулируемых источников тяги и вентиляционных дверей. Все модели реализованы численно и интегрированы в единый программный комплекс, предназначенный для решения сложных сетевых аэрологических задач, в том числе задач прогнозирования, профилактики и борьбы с рудничными авариями.

Ключевые слова: Теплообмен, пожар, воздухораспределение, выработанное пространство, естественная тяга, конвективная стратификация, сопряжение горных выработок, эжекиионный эффект, воздушно-депрессионная съёмка.

\section{Введение}

В целях обеспечения безопасности горных работ добыча полезных ископаемых в современных условиях сопровождается разработкой и внедрением новых технологических схем вентиляции с использованием дополнительных источников тяги и элементов регулирования воздухораспределения. В связи с увеличением количества аварий, связанных с гибелью шахтёров, особую значимость приобретают исследования, направленные на разработку систем контроля и управления движением воздуха с целью недопущения скоплений в нём взрывоопасных и вредных газов. Исследования процессов движения воздуха, переноса тепла, дыма, газов и пыли непосредственно во время аварий также востребованы, поскольку позволяют делать выводы относительно наиболее безопасных путей выхода людей на поверхность и способов скорейшей ликвидации аварий и их последствий.

Актуальность изложенного в статье материала обусловлена необходимостью создания новых, а также уточнения и совершенствования существующих методов прогнозирования изменений воздухораспределения и параметров рудничного воздуха во время аварий. Проведённые исследования аэро- и теплогазодинамических процессов, протекающих в аварийных режимах проветривания, в частности во время пожаров, позволили разработать комплекс мероприятий, направленных на предотвращение возникновения аварий и управление аварийным проветриванием в реальном времени.
Моделирование процессов переноса тепла и дыма по выработкам вентиляционной сети при пожаре. При описании распространения дыма при пожаре за основу была взята представленная в [1] математическая модель нестационарного переноса газовых примесей по выработкам рудника, относящаяся к классу моделей идеального вытеснения. Алгоритм расчёта распространения примесей был скорректирован на предмет непостоянства скоростей движения воздуха по выработкам, величины которых изменяются в соответствии с возникающими в негоризонтальных выработках тепловыми депрессиями. Их величины определяются двумя механизмами - тепловыделением при пожаре и поглощением тепла горным массивом. Динамика горения не рассматривалась, т.е. считалось, что интенсивность тепловыделений известна и является заданной функцией времени и координаты. При расчёте теплообмена рудничного воздуха с горным массивом был использован подход [2], заключающийся в численном решении задачи сопряжённого теплообмена с помощью преобразований Лапласа. Применительно к описанию пожара в модель нестационарного теплообмена были внесены следующие изменения и дополнения: 1) ввиду малости времени продолжительности пожара цилиндрическая задача теплообмена сведена к плоской; 2) учтено наличие источников переменных тепловыделений в выработках; 3) учтено непостоянство скоростей движения воздуха по выработкам в процессе теплообмена. 
Задача моделировалась следующим образом (рис. 1). В полупространстве массива с объёмной теплоёмкостью $c_{v}^{m}$, Дж/(град·м $\left.{ }^{3}\right)$ и температуропроводностью $\chi_{m}, \mathrm{M}^{2} / \mathrm{c}$ пройдена плоская выработка высотой $2 h$, м, расположенная по оси $z$, м. Подобие формы плоского слоя цилиндрическому соблюдается при равенстве толщины слоя радиусу выработки. При этом соотношения объёмов воздуха и поверхностей теплообмена в обоих случаях одинаковы. В начало выработки по оси $Z$ подаётся воздух со скоростью $v=v(t), \mathrm{M} / \mathrm{c}$, температурой $\left.T_{0}=T_{0}(t)\right),{ }^{\circ} \mathrm{C}$ и объёмной теплоёмкостью $c_{v}^{a}$, Дж/(град·м $\left.{ }^{3}\right)$.

Предполагается, что в начальный момент времени $t=0$ весь массив имеет одинаковую температуру $T_{\infty},{ }^{\circ} \mathrm{C}$ и весь воздух в выработке, за исключением сечения $Z=0$, имеет ту же температуру $T_{\infty}$. $\mathrm{B}$ сечении $z=0$ в начальный момент времени температура воздуха равна $T_{0}(0)$ и, в дальнейшем, изменяется со временем как $T_{0}(t)$. Пожар в выработке задаётся функцией тепловыделения $W=W(t, z)$, Дж/(c· $\left.{ }^{3}\right)$. Для упрощения математической записи задачи использовались безразмерные переменные: расстояние по $x$ и по $z$ измеряется в $h$ (полувысота слоя), время - в $h^{2} / \chi_{m}$, а единица измерения $\mathrm{W}-\frac{\chi_{m} c_{v}^{a}}{h^{2}}$. Температура отсчитывается от $T_{\infty}$. Уравнение теплопроводности в массиве, начальные и граничные условия для температур массива $T_{m}$ и воздуха $T$ имеют вид

$$
\frac{\partial T_{m}}{\partial t}=\frac{\partial^{2} T_{m}}{\partial x^{2}}
$$

$$
\begin{gathered}
\left.\left(a(t) \frac{\partial T}{\partial z}+\frac{\partial T}{\partial t}\right)\right|_{x= \pm 1}= \pm\left. b \frac{\partial T_{m}}{\partial x}\right|_{x= \pm 1}+W, \\
T(x= \pm 1, t, z=0)=T_{0}(t), \\
T_{m}(x, t=0, z)=T(x, t=0, z \neq 0)=0
\end{gathered}
$$

с дополнительным граничным условием, определяющим скачок температур между $T$ и $T_{m}$ на границе,

$$
\left.c\left(T-T_{m}\right)\right|_{x= \pm 1}= \pm\left. b \frac{\partial T_{m}}{\partial x}\right|_{x= \pm 1} .
$$

Полученное с помощью преобразований Лапласа безразмерное выражение для определения температуры воздуха $T$ как функции времени $t$ и координаты $z$ имеет вид нелинейного интегродифференциального уравнения (источник пожара локализован и помещён в начало выработки $z=0$ ):

- воздух движется в сторону возрастания $Z$ от источника тепла $(a>0)$

$$
\begin{aligned}
& T(t, z)=\frac{1}{2 \pi i} \int_{1 / t-i \infty}^{1 / t+i \infty}\left(\tau_{0}(p)+\frac{\omega(p, z=0)}{\bar{a}(p, z=0)}\right) \times \\
& \times \exp \left\{p t-\left(p+\frac{c \sqrt{p}}{c / b+\sqrt{p}}\right) \int_{0}^{z} \frac{d \zeta}{\bar{a}(p, \zeta)}\right\} d p ;
\end{aligned}
$$

- воздух движется в обратном направлении к источнику тепла $(a<0)$

$$
\begin{aligned}
& T(t, z)=\frac{1}{2 \pi i} \int_{1 / t-i \infty}^{1 / t+i \infty} \tau_{0}(p) \times \\
& \times \exp \left\{p t+\left(p+\frac{c \sqrt{p}}{c / b+\sqrt{p}}\right) \int_{z}^{L} \frac{d \zeta}{\bar{a}(p, \zeta)}\right\} d p .
\end{aligned}
$$

Формулы содержат следующие безразмерные комплексы:

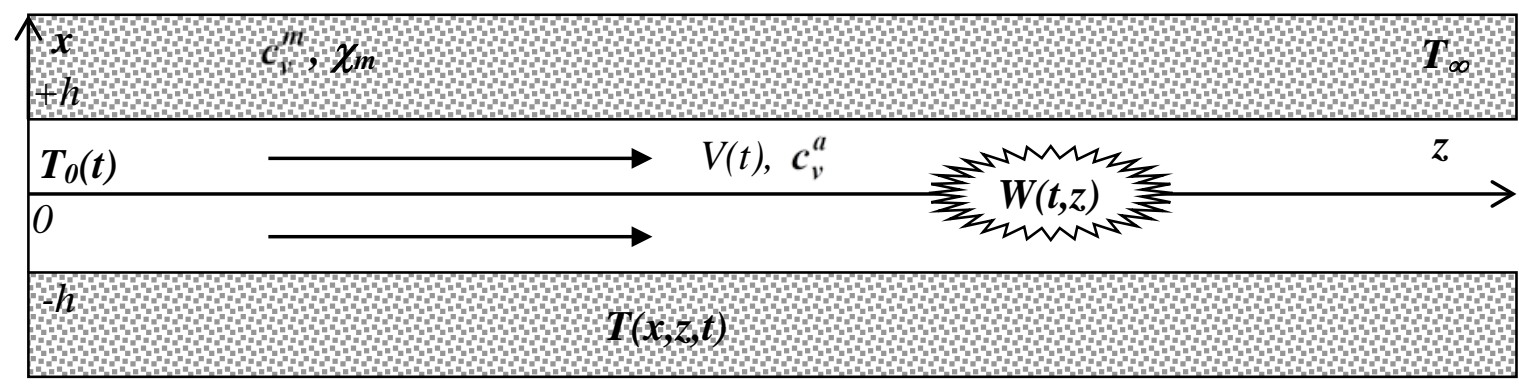

Рис. 1. Теплообмен воздуха с массивом в плоском слое 
$\bar{a}(\mathrm{p}, \zeta) \equiv \frac{\int_{0}^{+\infty} a(t) \frac{\partial T(t, \zeta) e^{-p t}}{\partial \zeta} d t}{\int_{0}^{+\infty} \frac{\partial T(t, \zeta) e^{-p t}}{\partial \zeta} d t}$

$\tau_{0}(\mathrm{p}) \equiv \int_{0}^{+\infty} T_{0}(t) e^{-p t} d t$

и $\omega(\mathrm{p}, z=0) \equiv \int_{0}^{+\infty} W_{0}(t) e^{-p t} d t-$ изображе-

ния начальной температуры

$T_{0}(t)=T(t, z=0)$ и локализованного в

начале выработки источника выделения

тепла $W_{0}(t)=\lim _{z_{0} \rightarrow 0} \int_{0}^{z_{0}} W(t, z) d z, \quad a(t) \equiv \frac{v(t) h}{\chi_{m}}$,

$b \equiv \frac{c_{v}^{m}}{c_{v}^{a}}, \quad c \equiv \frac{\alpha(t) h}{c_{v}^{a} \chi_{m}} . \quad \alpha(t)-$ коэффициент

теплоотдачи, Дж/( $\left.\mathrm{s}^{2} \cdot \mathrm{c}^{\circ}{ }^{\circ} \mathrm{C}\right), L-$ безразмерная длина выработки (отнесённая к $h$ ).

Для определения коэффициента теплоотдачи $\alpha=\alpha(t) \quad$ в расчётах была использована зависимость $\alpha\left(\frac{Д ж}{\mu^{2} \cdot c \cdot 2 p a \partial}\right)=2,6 \frac{|v(t)|(M / c)^{0,8}}{h(M)^{0,2}}$, приведённая в [3] для чисел Рейнольдса $\operatorname{Re}=\frac{|v(t)| D}{\eta}>10^{4}$, где $\eta=1,5 \cdot 10^{-5} \mathrm{~m}^{2} / \mathrm{c}-$ кинематическая вязкость воздуха.

Полученное решение задачи сопряжённого теплообмена вентиляционного воздуха и горного массива совместно с алгоритмом расчёта распространения газовой примеси и разработанным в отделе аэрологии и теплофизики Горного института программного обеспечения для расчёта воздухораспределения в сети позволяет рассчитывать изменения расходов и температуры воздуха, а также концентрации дыма в выработках рудника после возникновения пожара.

С помощью разработанной модели теплообмена проведены расчеты воздухораспределения и теплового режима с учетом развития горных работ и введения в эксплуатацию новых стволов на шахтах «Верхняя» и «Глубокая» рудника «Скали- стый» «Талнахского» рудоуправления ОАО «Норильский никель», на основании которых предложены технические мероприятия по улучшению качества проветривания рабочих зон. Разработаны также технические и технологические мероприятия по приведению температуры воздуха в горных выработках нефтяных шахт Нефтешахтного управления «Яреганефть» ООО «ПечорНИПИнефть» до значений, предусмотренных правилами безопасности.

Моделирование динамики выхода воздушных масс из выработанных пространств рудника после остановки или реверсирования источника тяги нагнетательного действия. Оценка газовой обстановки в аварийных режимах проветривания рудников, связанных со сменой режима работы главной вентиляционной установки, должна основываться на представлении воздуха в виде сжимаемой среды. Быстрое изменение депрессии или напора вентилятора инициирует процессы сжатия-разрежения воздуха, интенсивность которых сравнима по величине с общим изменением движения воздушных потоков за счёт изменения тяги. В случаях отключения или реверсирования нагнетающего источника тяги из непроветриваемых выработанных пространств рудника выделяется значительное количество застойного воздуха с высокой концентрацией вредных и горючих газов, что представляет опасность в случае превышения ими предельно допустимых концентраций в действующих выработках [4].

Несложный аналитический расчёт позволяет сделать оценку величины скорости и времени истечения сжатого воздуха из большой замкнутой полости (рис. 2). При сопротивлении пути выхода в 0,01 кмюрг истечение воздуха из выработанного пространства объёмом 1 млн кубических метров после остановки вентилятора нагнетательного действия происходит по расчёту в течение 10 минут. Приведённый пример даёт количественную оценку влияния сжимаемости воздуха на его движение после отключения источника тяги, но не отражает всей 


$$
\begin{aligned}
& \boldsymbol{V} \quad Q(t)=\sqrt{\frac{P_{0}}{R}} \operatorname{tg}\left(\operatorname{arctg} \sqrt{\frac{P_{H}-P_{0}}{P_{0}}}-\frac{t}{2 V} \sqrt{\frac{P_{0}}{R}}\right) \\
& P(t) \\
& \rho(t) \\
& \begin{array}{ll}
\longrightarrow, Q(t) & P_{0} \\
& \rho_{0}
\end{array} \\
& T=2 V \sqrt{\frac{R}{P_{0}}} \operatorname{arctg} \sqrt{\frac{P_{H}-P_{0}}{P_{0}}}
\end{aligned}
$$

Рис. 2. Выход избыточного количества воздуха из выработанного пространства рудника: $t$, $c$ - текущее время, область определения от 0 до T; T, с-время выхода избыточного воздуха из выработанного пространства; $Q(t), \mathrm{m}^{3} / c$ - текущий расход воздуха из выработанного пространства в рудничную сеть, $R, \kappa 2 / M^{7}$ - аэродинамическое сопротивление пути, соединяющего выработанное пространство с сетью;

$V, m^{3}$ - объем выработанного пространства; $P_{0}$, Па - внешнее давление воздуха на выходе; $P_{H}>P_{0}$, Па - начальное давление воздуха в выработанном пространстве; $\rho_{0}, \kappa 2 / \mathrm{s}^{3}-$ плотность внешнего воздуха на выходе; $\rho_{H}>\rho_{0} \kappa 2 / \mathrm{M}^{3}$ - начальная плотность воздуха в выработанном пространстве

сложности процесса, т.к. в реальности: 1) выработанное пространство - это не просто большая воздушная полость, а сложная система выработок, каждая из которых имеет внутреннее аэродинамическое сопротивление; 2) система эта связана с действующими выработками не в одном, а в нескольких местах; 3) сжатие воздуха происходит не только в выработанном пространстве, но и в действующих выработках. Поэтому точное решение возможно лишь на основе численного решения задачи в сетевой постановке.
В целях упрощения ресурсоёмкости модели воздух полагается сжимаемым только в сопряжениях выработок, вмещающих в себя половину массы рудничного воздуха прилегающих выработок. Стоки и истоки воздуха в сопряжениях задаются поправками в уравнениях 1-го закона сетей, определяющими интенсивность сжатия или разрежения воздуха в узлах под действием сил давления. В систему уравнений Кирхгофа [5] добавлены инерционное слагаемое в контурных уравнениях и ненулевой баланс расходов в сопряжениях, моделирующий сжимаемость воздуха (рис. 3).

$$
\left\{\begin{array}{c}
\sum_{j}\left( \pm q_{j, k}^{(s)}\right)=-\frac{\widehat{P_{k}^{(s)}\left(\left\{q_{j}\right\}\right)-P_{k-1}^{(s)}} \frac{\rho_{k-1}^{(s)}}{2 P^{(0)}} \sum_{j} L_{j}^{(s)} S_{j}^{(s)}}{\sum_{j}( \pm)\left(\frac{R_{j}(t)}{\left(\bar{\rho}_{j, k-1}\right)^{2}} q_{j, k}^{(i)} \mid q_{j, k}^{(i)}\left(+\frac{q_{j, k}^{(i)}-q_{j, k-1}^{(i)}}{t_{k}-t_{k-1}} \frac{L_{j}}{S_{j}}\right)=\sum_{j}\left( \pm \Delta \pi_{j, k}^{(i)}\left(q_{j}, t\right)\right)\right.}
\end{array}\right.
$$

Рис. 3. Законы вентиляционных сетей для расчета нестационарного движения потоков сжимаемого воздуха в руднике: $k, j, s, i$ - номера моментов времени, выработок (от 1 до n), сопряжений (от 1 до v-1 и независимых контуров (от 1 до $n-(v-1)) ; R(t)\left(\kappa 2 / м^{7}\right), \Delta \pi(q, t)(\Pi а), q(t)(\kappa 2 / c)$ - аэродинамические сопротивления выработок, напоры источников тяги и искомые значения массовых расходов воздуха;

$\rho(t) u \rho(t)\left(\kappa 2 / M^{3}\right)$ - плотность воздуха в сопряжении и средняя плотность воздуха по выработке; $t(c) L(m), S\left(\mu^{2}\right)$ - время, длины и сечения выработок; $P^{(0)}(\Pi а), P(t)(П а)-$ атмосферное давление и давление воздуха в сопряжении 
Быстро сходящиеся специализированные методы проведения вентиляционных расчётов (последовательных приближений, контурных расходов, узловых давлений или градиентные [6-10]) для решения этой системы уравнений непригодны, поскольку предполагают нулевой баланс расходов в узлах сети, поэтому используется стандартный метод Ньютона [11]. На каждом шаге по времени производятся увязка расходов воздуха по всем выработкам, при этом в ней участвуют: 1) напоры источников тяги, если они заданы напорными характеристиками; 2) аэродинамические сопротивления выработок, если в них находятся регулируемые вентиляционные двери (при моделировании работы систем автоматического управления проветриванием); 3 ) давление воздуха в сопряжениях, которое определяется на каждой итерации по сумме падений депрессии в выработках, соединяющих текущий узел с атмосферой с фиксированным значением давления и 4) плотности воздуха в сопряжениях, уточняющие баланс расходов и потери де- прессии на линейных аэродинамических сопротивлениях выработок. По сути, представленная модель нестационарного движения потоков сжимаемого воздуха является интегральным аналогом дифференциальных уравнений гидравлического удара, в которых пространственная сетка укрупнена до размеров выработок $[12,13]$.

На рис. 4 приведены результаты расчёта движения воздушных потоков в выработках модельной сети после останова и реверсирования вентилятора. Выработка № 2 обозначает выработанное пространство объёмом 20 млн м ${ }^{3}$, напор источника тяги 500 даПа направлен сначала на сжатие воздуха в выработанном пространстве. Смоделированы варианты: 1) остановки вентилятора и 2) его реверсирования до депрессии той же величины. При остановке ГВУ, как и для случая одной выработки, динамика расходов характеризуется конечным временем прекращения движения воздуха в течение 20 мин., уменьшение расхода происходит линейно, что согласуется с полученными аналитическими зависимостями
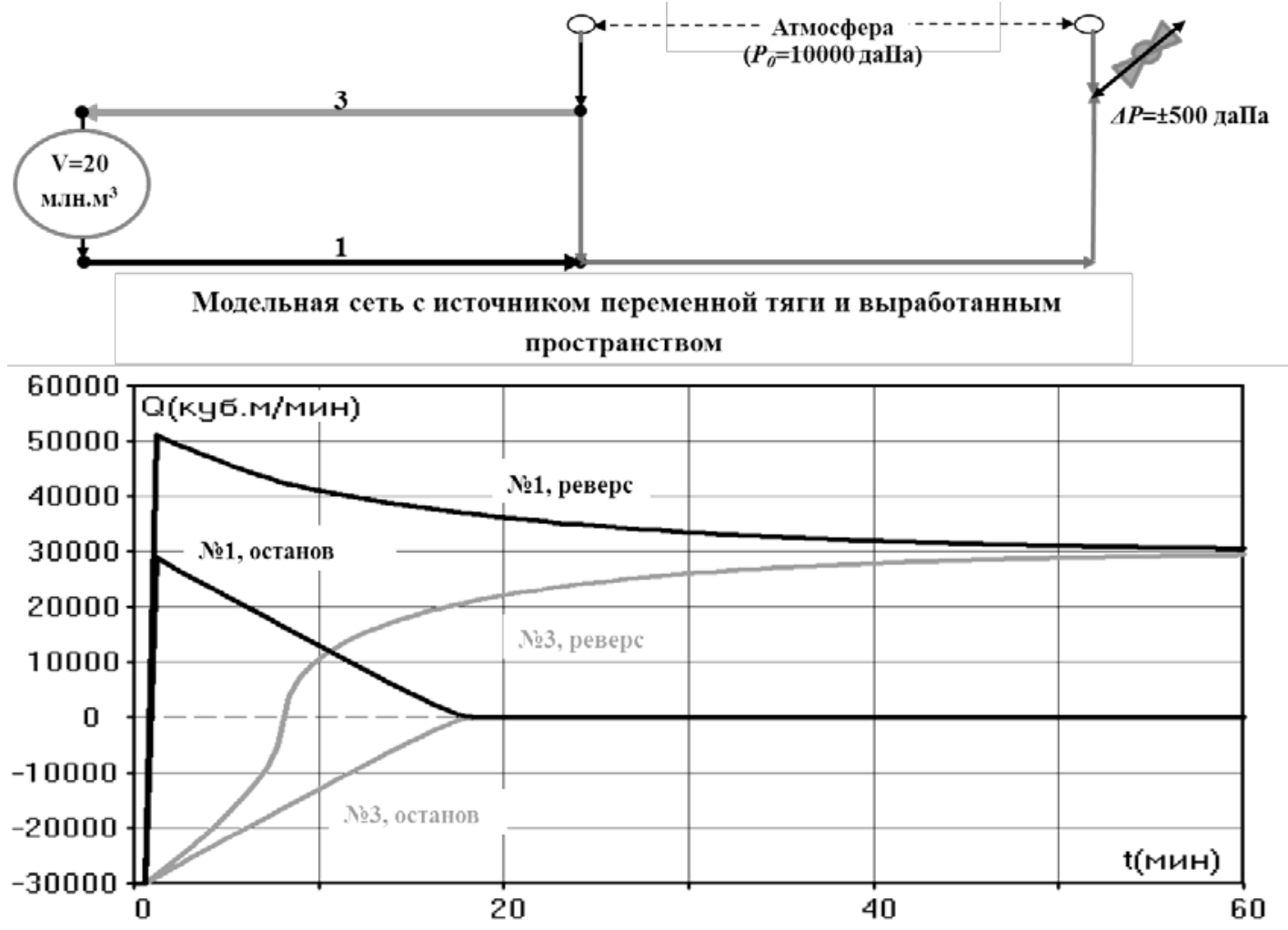

Рис. 4. Динамика расходов воздуха на выходе из выработанного пространства после останова и реверсирования ГВУ 
(см. рис. 2). Динамика реверсивного движения воздуха отличается качественно и количественно, время протекания переходного процесса значительно больше, режим релаксации нелинеен с асимптотическим выходом на стационарный режим.

По результатам проведённых исследований способов моделирования нестационарного воздухораспределения в вентиляционных сетях рудников $[12,14-16]$ установлено, что оптимальное сочетание точности и скорости расчёта даёт полуаналитическая модель движения сжимаемых воздушных потоков, построенная на решении алгебраических сетевых уравнений с поправками на инерционность и сжимаемость. Физически обоснованная структура поправок обеспечивает адекватность расчётных результатов применительно к распределению расходов между выработками.

С целью верификации полученных результатов была проведена серия сезонных замеров расходов и температур воздуха в стволах и выработках околоствольного двора на руднике РУ-3 ОАО «Беларуськалий» после отключения вентилятора главного проветривания. Во всех замерах зафиксировано, что после отключения источника общешахтной депрессии избыточное разряжение начинает заполняться воздухом и сопровождается опрокидыванием исходящей струи. Согласно экспериментальным данным переходный режим опрокидывания струи в вентиляционном стволе длится порядка нескольких минут, после чего устанавливается стационарный режим движения воздуха за счёт естественной тяги.

\section{Конвективная воздушных потоков стратификация горных выработок, ё роль в формировании тепловых депрессий и влияние на устойчивость проветрива-} ния. В основе стандартных методов численного расчёта воздухораспределения в рудничных вентиляционных сетях лежат, как правило, одномерные модели, в которых воздух по выработкам движется как единое целое, вперёд или назад, не имея других степеней свободы [17]. Та- кой подход позволяет рассчитывать тепловые депрессии и решать нестационарные задачи, связанные с моделированием переходных вентиляционных процессов, однако некоторые особенности протекания этих процессов остаются неучтёнными. Это, прежде всего, локальное конвективное движение воздуха внутри выработок, которое в рамках одномерной модели отсутствует. Влияние локальной конвекции на сквозное движение воздуха неоднозначно и может быть, в зависимости от условий, как существенным, так и незначительным. Например, при моделировании движения воздуха в следующих условиях возможность возникновения локальной конвекции, очевидно, будет играть решающую роль: 1) естественная тяга в руднике с одноуровневыми стволами с выключенным вентилятором главного проветривания; 2) пожар в горизонтальной выработке.

1. Расчёт с помощью одномерной модели воздухораспределения в сети показывает, что в руднике с одноуровневыми стволами с выключенным вентилятором возникает сквозное проветривание естественной тягой при низкой температуре наружного воздуха. Первоначальное неустойчивое состояние покоя, когда более плотные слои воздуха находятся сверху, нарушается малейшим возмущением, поступление воздуха в рудник начинает возрастать и в течение нескольких минут выходит на стационарный режим проветривания естественной тягой. Направление движения воздуха через рудник определяется направлением возмущения, в качестве которого в расчёте выступает кратковременно включаемый маломощный источник тяги. Скорость установившегося стационарного режима проветривания определяется интенсивностью теплообмена вентиляционного воздуха с горным массивом. Однако в данном случае ясно, что неучет возможности возникновения внутристволовой конвекции является слишком грубым приближением, чтобы рассчитывать на соответствие одномерной модели проветривания реальности. Очевидный сценарий такого движения: холодный воздух проваливается вниз 
по центру ствола, тёплый - поднимается вверх вдоль стенок. Локальная конвекция будет происходить в обоих стволах, и уже не факт, что малое возмущение разрушит это движение и приведёт к возникновению естественной тяги, а если и приведёт, то интенсивность сквозного проветривания окажется значительно ниже полученного с помощью одномерной модели по энергетическим соображениям.

2. Пожар в горизонтальной выработке, по которой воздух не движется (или движется очень медленно), в рамках одномерной модели безопасен, поскольку не приводит к выносу тепла и дыма из выработки. Горение прекращается из-за недостатка кислорода. В реальности же при таком пожаре возникает мощное движение воздуха от источника возгорания под кровлей, и к источнику возгорания - по почве выработки. В результате тепло и дым выносятся из выработки в обе стороны, а свежий воздух поступает с обеих сторон и поддерживает горение. Правда, чем длиннее выработка, тем сильнее теплообмен и перемешивание встречных потоков и, значит, слабее вынос, но это уже относится к особенностям моделирования движения воздуха, которое согласно приведённым аргументам должно быть в данном случае не одномерным. В противном случае построенная модель пожара действительности соответствовать не будет.

Причиной расслоения воздушных потоков по сечению выработок является пере- пад плотностей нагретого до разных температур воздуха. Холодный воздух опускается, а тёплый поднимается, занимая его место, результирующее движение образует конвективный вихрь, который принимается за составляющий элемент искомого теплового движения. Расслоение возникает при наложении этого вихря на основное сквозное движение воздуха по выработке. Если линейная скорость вихря $\Delta v_{i}$, то первоначально одинаковая по всему сечению скорость воздуха $v_{i}$ изменяется на $v_{i}+\Delta v_{i}$ в одной половине сечения и на $v_{i}-\Delta v_{i}-$ в другой. Очевидно, что $\Delta v_{i}$ не является константой по длине выработки, а будет убывать с удалением от источника выделения тепла, поэтому представление расслоения одним простым большим вихрем было бы неправильно. Действительно, слои движущегося с разными скоростями воздуха (при сильной конвекции - встречными) не могут не перемешиваться по ходу своего движения, в результате чего расслоение неизбежно уменьшается. Эта особенность может быть учтена на основе представления конвективного движения воздуха в виде каскадной суперпозиции элементарных вихрей в пределах одной пространственной ячейки. Генератором конвекции будет являться продольный градиент средней по сечению температуры воздуха.

По рис. 5, на котором изображена одна ячейка наклонной выработки, можно оценить скорость образующегося вихря. Пусть выработка наклонена под углом $\alpha$

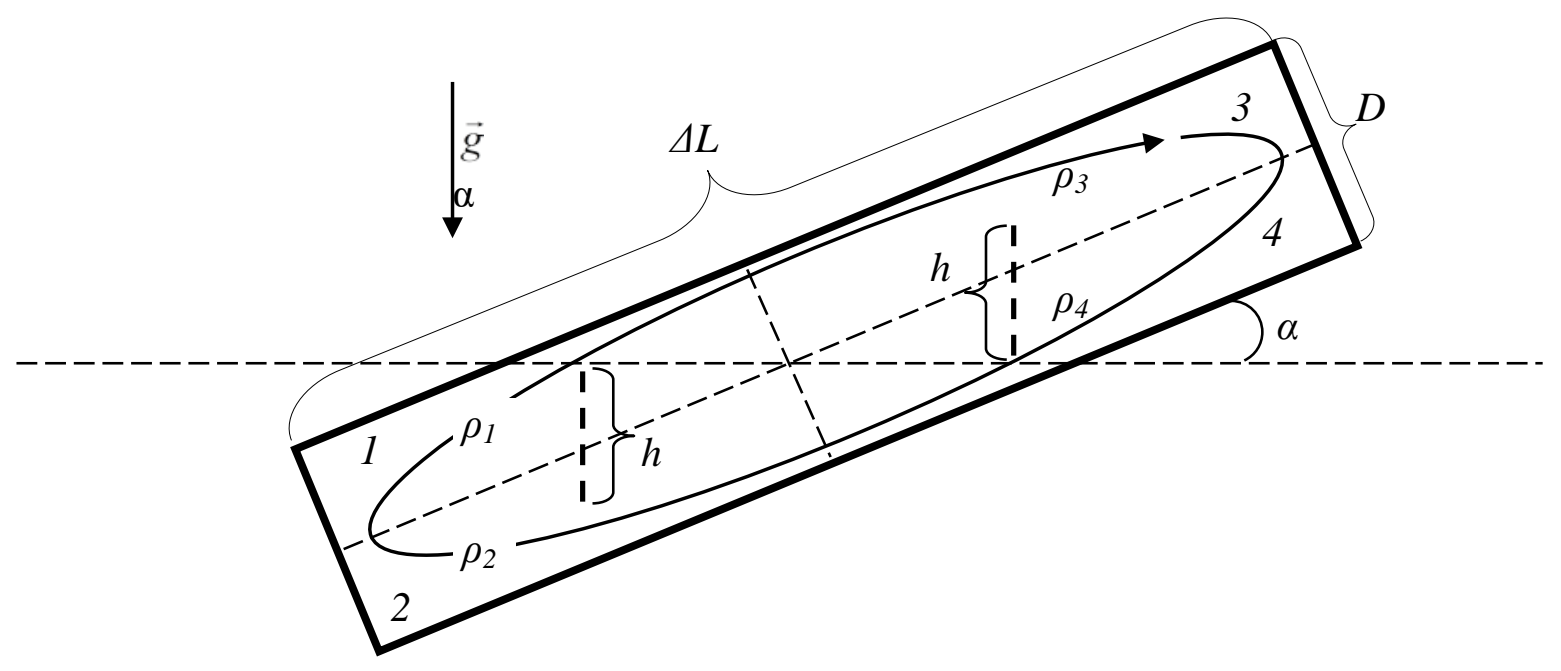

Рис. 5. Образование конвективного вихря в элементарной ячейке наклонной выработки 
к горизонту, который может находиться в пределах от 0 (горизонтальная выработка) до $90^{\circ}$ (вертикальная выработка). Знаки средних по сечению скорости движения воздуха $v$ и градиента температур $\nabla T,{ }^{\circ} \mathrm{C} /$ м могут быть любые. В соответствии с законом сохранения энергии кинетическая энергия образующегося вихря равна разности потенциальных энергий двух градиентных частей (1-2 и 3-4) воздуха со средними по сечению выработки плотностями $\rho_{1}=\rho_{2}<\rho_{3}=\rho_{4}, \quad \kappa г / \mathrm{M}^{3}$, если температура возрастает вниз по рисунку, и двух других, образующихся после конвективного перемещения частей $(1 \rightarrow 3$, $3 \rightarrow 4,4 \rightarrow 2,2 \rightarrow 1)$, при котором более лёгкий воздух занимает верхнее положение, а более тяжёлый - опускается вниз. При обратном соотношении плотностей $\rho_{1}=\rho_{2}>\rho_{3}=\rho_{4}(\nabla T$ направлен вверх $)$ конвективный вихрь не образуется. Уменьшение потенциальной энергии $\Delta H$ (Дж) выделенной ячейки после перемещения воздуха будет определяться взаимным замещением её фрагментов $3 \leftrightarrow 2$ :

$$
\Delta H=\frac{g}{2} h D^{2} \Delta L\left(\rho_{\theta}-\rho_{H}\right),
$$

где $g=9,8, \mathrm{~m} / \mathrm{c}^{2}-$ ускорение свободного падения, $D$ - поперечный размер выработки, м, $\Delta L$ - продольный размер выделенной ячейки, м, $\rho_{8}=\rho_{3}=\rho_{4}$ и $\rho_{H}=\rho_{1}=\rho_{2}-$ плотности верхней и нижней частей ячейки, $h$ - расстояние от центра масс меняющихся местами фрагментов 2 и 3 от горизонтальной оси, проведённой через центр ячейки, м. По геометрическим соображениям

$$
h=\frac{1}{4}(\Delta L \sin \alpha+D \cos \alpha) .
$$

Кинетическая энергия, Дж образующегося в результате вихря имеет две составляющие: $E_{6}=\frac{\rho_{t} v^{2}}{4} D^{2} \Delta L$ - от движения (со скоростью $v, \mathrm{~m} / \mathrm{c}$ ) лёгкого тёплого воздуха под кровлей выработки (вправо) и $E_{н}=\frac{\rho_{s} v^{2}}{4} D^{2} \Delta L-$ от движения (тоже со скоростью $v$ ) тяжёлого холодного воздуха над почвой выработки (влево). Значит, общая кинетическая энергия вихря равна:

$$
E=\frac{\left(\rho_{\theta}+\rho_{H}\right) v^{2}}{4} D^{2} \Delta L .
$$

Скорость вихря выражается через геометрические параметры ячейки и плотности воздуха в ней после подстановки (2) в (1) и приравнивания энергий (1) и (3):

$$
v=\sqrt{\frac{g}{2} \frac{\rho_{B}-\rho_{H}}{\rho_{B}+\rho_{H}}(\Delta L \sin \alpha+D \cos \alpha)} .
$$

Полученное значение $v$ с учётом знака определяет конвективное расслоение воздушного потока по сечению выработки. Если $v$ по модулю превышает среднее значение скорости воздуха и обратно ему по знаку, то потоки двигаются в разных направлениях.

Учёт конвективной стратификации воздушных потоков по высоте горных выработок оказывается крайне важным при численном моделировании вентиляционных процессов во время рудничных пожаров, поскольку позволяет прогнозировать распространение дыма и тепла в направлениях, противоположных средним расходам воздуха.

Анализ данных проведённых экспериментальных исследований естественной тяги на руднике РУ-3 после отключения вентилятора в холодный период года подтверждает модельный сценарий теплового движения воздуха - тяжёлый холодный воздух опускается по центру ствола, а лёгкий тёплый поднимается вверх вдоль стенок. В результате интенсивного конвективного перемешивания встречных потоков воздуха в верхних частях воздухоподающего и вентиляционного стволов образуются столбы воздуха разной плотности, создающие весовой напор и устойчивую рециркуляцию воздуха через горные выработки верхнего горизонта, наличие которой было отмечено в ходе проведения воздушно-депрессионной съёмки рудника.

Моделирование падения депрессии на сопряжениях горных выработок. Расчёт воздухораспределения в вентиля- 
ционной сети невозможен без знания аэродинамических сопротивлений её отдельных элементов. Элементами рудничной вентиляционной сети являются горные выработки либо группы соседних выработок, объединённых по какому-нибудь характерному признаку. Сопротивления выработок определяются по результатам воздушно-депрессионных съёмок (ВДС), а также расчётным способом с использованием зависимостей, полученных на основании обработки многочисленных экспериментальных данных [18]. Как правило, при проведении обработки результатов ВДС и составлении расчётных схем вентиляционных сетей считается, что потери депрессии приходятся лишь на трение движущегося воздуха о стенки выработок, т.е. учитываются только линейные сопротивления. Однако, как показывают экспериментальные исследования, вклад местных сопротивлений изгибов, тройников, сужений и расширений в распределение расходов воздуха не так уж мал, составляет, например, для калийных рудников приблизительно $30 \%$ и возрастает с увеличением сечения выработок. Определение этих сопротивлений из результатов ВДС представляется затруднительным по причине невозможности их явного выделения из линейных сопротивлений выработок. Поэтому основной способ определения сопротивлений сопряжений - это расчёт по формулам.

Имеющиеся в литературе по рудничной вентиляции зависимости для определения аэродинамических сопротивлений сопряжений выработок ограничиваются несколькими вариантами плоских тройников [19]. Вид и единообразие коэффициентов свидетельствуют о том, что зависимости носят не экспериментальный, а эмпирический характер. Не соблюдены также условия симметрии между формулами относительно смены знаков расходов и их обнуления. В литературе по гидравлическим сопротивлениям [6] число рассмотренных вариантов сопряжений значительно больше и приводимые зависимости и коэффициенты, очевидно, экспериментального происхождения.

Однако перенос указанных гидравлических формул на вентиляцию выработок большого сечения вряд ли уместен. Кроме того, предлагаемые зависимости для расчётов местных сопротивлений представляют собой отдельные для каждого случая формулы, никак не связанные и не согласующиеся между собой в предельных случаях. Поэтому интеграция их в процедуру численного расчёта воздухораспределения в вентиляционных сетях в таком виде однозначно обрекает её на расходимость в случае неопределённости направлений движения воздуха по выработкам. А при наличии хотя бы двух источников тяги в сети, как правило, такая неопределённость уже имеет место. Причина расходимости итерационной процедуры в данном случае - скачок потерь депрессии на сопряжении при смене знаков расходов, исключить который, используя известные зависимости, не представляется возможным.

С целью устранения указанной проблемы разработан упрощённый подход к моделированию сопротивлений сопряжений (узлов сети). В некоторых случаях потери энергии при движении потока воздуха могут быть вычислены исходя из закона сохранения импульса [20]. Чем меньше доля взаимодействия воздуха со стенками по сравнению с взаимодействием воздушных потоков между собой, тем точнее будет такой расчёт. Исходя из этих соображений, можно смоделировать потери энергии не только на сужениерасширение потока, но и на смешиваниеразделение. Для этого произвольное сопряжение выпрямляется - в одну сторону направляются входящие в узел выработки, в другую - исходящие. Потери на изгиб при этом исчезают, а для выпрямленного узла может быть записан закон сохранения импульса:

$$
-\rho \mathrm{v}_{i} q_{i}+\frac{q_{i}}{Q} \sum_{j} \rho \mathrm{v}_{j} q_{j}=10 S_{i} \Delta P_{i},
$$


где $i$ и $j$ - индексы, соответствующие выработкам с исходящими и входящими в узел потоками воздуха, $v_{i}, v_{j}-$ скорости $(\mathrm{M} / \mathrm{c}), q_{i}=v_{i} S_{i}, q_{j}=v_{j} S_{j}-$ объёмные расходы, $\mathrm{M}^{3} / \mathrm{c}, Q=\sum_{j} q_{j}=\sum_{i} q_{i}-$ общий объёмный расход воздуха через узел, $\mathrm{m}^{3} / \mathrm{c}, \rho-$ плотность воздуха, кг/м ${ }^{3}, S_{i}$, - сечение $i$-й выработки, м², $\Delta P_{i}$ - перепад статических давлений между сопряжением и исходящей выработкой, даПа. В рамках данной модели сопротивление узла определяется только исходящими $i$-ми участками. Сопротивления входящих $j$-х участков полагаются равными нулю. Таким образом, в предположении сохранения импульса изменение статического напора по исходящим выработкам имеет вид

$$
\Delta P_{i}=\frac{\rho q_{i}}{10 S_{i}}\left(-\frac{q_{i}}{S_{i}}+\frac{1}{Q} \sum_{j} \frac{q_{j}^{2}}{S_{j}}\right) .
$$

C учётом изменения кинетической энергии изменение полного напора будет $\Delta P_{i}+\left(\frac{\rho v_{i}^{2}}{20}-\frac{1}{Q} \sum_{j} \frac{\rho v_{j}^{2}}{20} q_{j}\right)$ с весовым коэффициентом $\frac{q_{i}}{Q}$, исключающим возможность скачка потери напора при изменении направления движения воздуха через узел, т.е.

$$
\Delta P_{i}^{\text {поли }}=\frac{q_{i}}{10 Q}\left(-\frac{\rho q_{i}^{2}}{2 S_{i}^{2}}+\frac{\rho}{Q}\left(\frac{q_{i}}{S_{i}} \sum_{j} \frac{q_{j}^{2}}{S_{j}}-\sum_{j} \frac{q_{j}^{3}}{2 S_{j}^{2}}\right)\right) .
$$

Несложные преобразования позволяют представить (4) в более наглядной и понятной с физической точки зрения симметричной форме:

$$
\Delta P_{i}^{\text {полн }}=-\sum_{j} \frac{q_{i} q_{j}}{Q^{2}} \frac{\rho\left(v_{i}-v_{j}\right)^{2}}{20},
$$

из которой очевидны следующие важные особенности (5), без соблюдения которых интеграция её с методами расчёта воздухораспределения в вентиляционной сети была бы невозможна:

- $\Delta P_{i}^{\text {полн }} \leq 0$ - смешивание-разделение потоков воздуха в узлах сети сопровождается всегда потерей энергии, исключения были бы физически абсурдны;
- потеря энергии в узле тем больше, чем больше определяющая величину сдвигового трения разность скоростей $\left|v_{i}-v_{j}\right|$ исходящего и входящего потоков;

- при обращении $q_{i}$ в ноль потеря напора также обращается в ноль, что исключает скачок напора при реверсировании потока и обеспечивает сходимость итерационной процедуры расчёта воздухораспределения;

- симметрия (5) относительно $q_{i}$ и $q_{j}$ также является гарантом плавного превращения при реверсировании исходящих из узла потоков воздуха во входящие и наоборот без нарушения сходимости.

Полученная зависимость позволяет производить количественный учёт влияния сопротивлений сопряжений произвольной размерности на распределение расходов воздуха в вентиляционной сети в единообразной форме при условии корректной интеграции её в соответствующий метод расчёта воздухораспределения.

Разработанная методика определения аэродинамических сопротивлений сопряжений горных выработок была апробирована в ходе проведения экспериментальных исследований сопротивлений рудников БКРПУ-4, БКПРУ-2 и СКРУ-3 в нормальном и реверсивном режимах проветривания. Поскольку данные сопротивления не симметричны относительно смены направлений движения воздушных потоков в отличие от линейных сопротивлений выработок, то реверс вентиляторов приводил к изменению расходов воздуха через рудники, измеренная величина которых соответствовала расчётным прогнозным значениям.

Проветривание выработок большого сечения с помощью вентиляторных установок, работающих без перемычки. Решение проблемы недостаточной подачи свежего воздуха на удалённые участки рудничных вентиляционных сетей является первостепенной задачей рудничной аэрологии. Для увеличения общего поступления воздуха в рудник наряду с 
использованием более мощных вентиляторов главного проветривания и вспомогательных подземных вентиляционных установок широкое применение получили компактные маломощные вентиляторы местного проветривания (ВМП). Цель работы такого вентилятора - перераспределение расходов воздуха, т.е. отбор воздуха с того направления, где его достаточно, и подача его в том направлении, где его не хватает. Как правило, ВМП устанавливается без перемычки, что увеличивает расход прокачиваемого вентилятором воздуха за счёт эжекционного эффекта, возникновение которого имеет место при соблюдении следующих двух условий: 1) аэродинамическое сопротивление проветриваемого участка должно быть достаточно мало (менее 0,01 кмюрг); 2) сечение выработки, в которой установлен ВМП, должно быть достаточно мало для обеспечения стеснённости струи вентилятора (порядка 10 м $^{2}$ и менее). Указанные условия свойственны более всего калийным рудникам, что и явилось причиной широкого использования в них ВМП в качестве эжектирующих установок для улучшения проветривания. В угольных шахтах сопротивления выработок существенно больше (первое условие не выполняется), и потому ВМП без перемычки в них менее эффективны, чем с перемычкой, и используются значительно реже [21].

Второе условие не выполняется в гипсовых шахтах, где сечения выработок рабочей зоны достигают $100 \mathrm{~m}^{2}$ и более, хотя сопротивления их, напротив, значительно меньше, чем в калийных рудни-

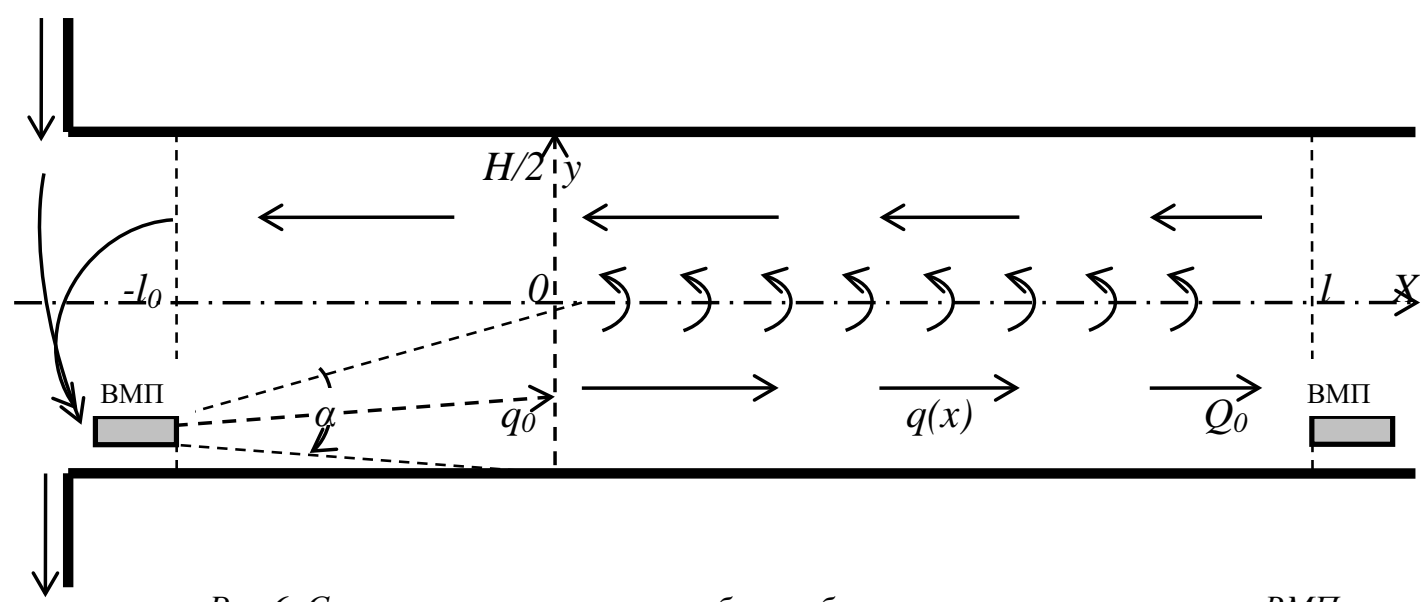

Рис.6. Схема проветривания выработки большого сечения с помощью ВМП ках. Несмотря на малую величину аэродинамического сопротивления гипсовых шахт, проблема недостаточного проветривания удалённых панелей здесь, также как и в других рудниках, стоит достаточно остро. Ситуация усугубляется тем обстоятельством, что ВМП в данном случае не могут быть размещены в перемычке, а реализация эжекционного эффекта в выработках большого сечения оказывается под вопросом. Струя вентилятора, направленная вглубь такой выработки, не достигая стенок выработки и иссякнув, частично или полностью возвращается на всас вентилятора, создавая бесполезную циркуляцию воздуха вокруг источника тяги. Проблема эта получила своё решение в применении последовательной установки ВМП друг за другом, позволяющей уменьшить циркуляцию, снизить утечки воздуха через отработанное пространство и обеспечить подачу воздуха к местам ведения горных работ. На сегодняшний день этот вид совместного включения вентиляторных установок широко используется на шахте ОАО «Кнауф Гипс Новомосковск».

В связи с необходимостью проведения оценочных расчётов эффективности подобного способа проветривания, возникает задача определения по известным дебитам $q_{0}$ ВМП необходимого расстояния между вентиляторами $l+l_{0}$ для обеспечения нужного расхода воздуха $Q_{0}<q_{0}$ по выработке. Физическая модель перемешивания встречных потоков воздуха (рис. 6) основывается на следующих приближениях: 
- струя расширяется до половины сечения выработки с неизменным расходом. После раскрытия струи движение воздуха представляет собой горизонтальное движение двух встречных потоков одинакового сечения;

- уменьшение расхода воздуха после раскрытия струи происходит в результате непрерывного перетекания воздуха из прямого в обратный поток в результате вязкого трения потоков между собой;

- коэффициент турбулентной вязкости на границе потоков моделируется так же как, и для свободной осесимметричной струи [22];

- на расстоянии уменьшения расхода воздуха до $Q_{0}$ ставится следующий вентилятор, передающий воздух дальше, и т.д.

Для определения длины $l_{0}$ участка раскрытия струи можно воспользоваться результатами исследований [23], согласно которым стеснённая струя расширяется до $40 \%$ сечения выработки на расстоянии

$$
l_{0}=\frac{0,2}{\operatorname{tg} \alpha / 2} H,
$$

где $H$ - высота выработки, м, $\alpha$ - угол раскрытия струи, ${ }^{\circ}$ (обозначения по рисунку). Для обычной струи $\alpha \approx 25^{\circ}$, а для настилающейся $-\alpha \approx 10 \div 12^{\circ}$, т.е. $l_{0}$ настилающейся струи в полтора раза больше, чем обычной. Таким образом, $l_{0} \approx 2 H$.

Далее определяется интенсивность перемешивания двух встречных потоков воздуха. Пусть $\Delta P(x)$ - перепад давлений по оси у между этими потоками, Па, который приводит к перетеканию воздуха из одного потока в другой (снизу - вверх по рисунку). В пренебрежении трением при перетекании:

$$
\Delta P(x)=\frac{\rho}{2} v_{y}^{2}(x),
$$

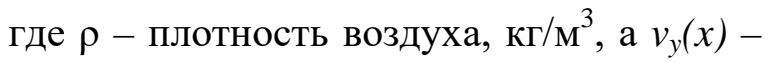
скорость перетекания, м/с, т.е. поперечная составляющая скорости воздуха $\vec{v}=\left(v_{x}, v_{y}\right)$. Положив $\frac{\partial v_{y}}{\partial y}=\frac{v_{y}}{H / 2}$ и воспользовавшись уравнением непрерывно- сти $\frac{\partial v_{x}}{\partial x}+\frac{\partial v_{y}}{\partial y}=0$, можно установить связь между продольной и поперечной компонентами скорости:

$$
v_{y}(x)=\frac{H}{2} \frac{\partial v_{x}}{\partial x} .
$$

Диссипативная функция (потеря энергии в результате трения в единице объёма воздуха в единицу времени)

$D(x)=\frac{\rho}{2} \eta(x)\left(\frac{\partial v_{x}(x)}{\partial y}\right)^{2}$, где $\eta(x)$ - турбулентная вязкость воздуха, ${ }^{2} / \mathrm{c}$, а производная по у может быть представлена как $\frac{\partial v_{x}(x)}{\partial y}=\frac{v_{x}(x)}{H / 2}$, после чего от частных производных можно перейти к обычным, поскольку зависимость по у снимается. За время $\Delta t$ давление $P$ уменьшится на $\delta P=D \Delta t=D \frac{\Delta x}{v_{x}}$, и, в силу симметрии между встречными потоками, можно заключить, что

$$
\frac{d(\Delta P(x))}{d x}=\frac{2 D(x)}{v_{x}(x)}=\frac{\rho \eta(x)}{v_{x}(x)}\left(\frac{2 v_{x}(x)}{H}\right)^{2} .
$$

После подстановки сюда $\Delta P(x)$ из (6) и $v_{y}(x)$ из (7) получается нелинейное дифференциальное уравнение второго порядка для $v_{x}(x)$ :

$$
\frac{d v_{x}(x)}{d x} \frac{d^{2} v_{x}(x)}{d x^{2}}=-\frac{16 \eta(x)}{H^{4}} v_{x}(x) .
$$

Коэффициент турбулентной вязкости $\eta(x)$ в приближении свободной турбулентности согласно [22] определяется по формуле

$$
\eta(x)=\frac{0,013}{2} H v_{x}(x) .
$$

Уравнение (8) решается аналитически с помощью замены $w(x)=\frac{d v_{x}(x)}{d x}$ и имеет экспоненциальное решение $v_{x}(x)=v_{0} e^{-0,47 x / H}\left(v_{0}=v_{x}(x=0)-\right.$ начальная скорость потока) или для расхода $q(x)=q_{0} e^{-0,47 x / H}$, где $q_{0}=q(x=0)-$ дебит вентилятора. Учитывая, что $x$ не содержит участок раскрытия настилающейся 
струи $2 H$, выражение для определения необходимого для обеспечения расхода воздуха $Q_{0}$ по выработке расстояния между ВМП принимает вид:

$$
l+l_{0}=2 H+\frac{H}{0,47} \ln \frac{q_{0}}{Q_{0}} .
$$

Например, при $H=10$ метров и $q_{0}=1500 \mathrm{~m}^{3} /$ Мин. (ВМЭ-12А) из (10) следует, что для обеспечения расхода воздуха $Q_{0}=500 \mathrm{~m}^{3} /$ мин. вентиляторы необходимо расположить на расстоянии $l+l_{0}$ не далее 45 метров друг от друга. Если достаточен расход $Q_{0}=150 \mathrm{~m}^{3} /$ мин., то $l+l_{0}$ может быть увеличено до 70 метров.

Аналитическая модель проветривания отработанного пространства гипсовых рудников была протестирована серией численных экспериментов в программном комплексе SolidWorks, подтвердивших, что с помощью каскада последовательно установленных вентиляторов может осуществляться транспортировка воздуха на произвольные расстояния в выработках с большим аэродинамическим сопротивлением пути замыкания, в том числе и тупиковых.

Интерактивный метод планирования проведения и обработки результатов воздушно-депрессионной съёмки рудника. Организация проветривания современных горнодобывающих предприятий является многофакторной задачей, трудоёмкость решения которой обусловлена сложностью и динамичностью структуры сети горных выработок. Количество и протяжённость выработок меняется со временем по мере эксплуатации рудника, разрабатываются новые добычные участки, появляются новые выработки, закладывается выработанное пространство, возводятся вентиляционные перемычки. В результате меняется аэродинамическое сопротивление рудника, как в целом, так и частично - по горизонтам, рабочим панелям и отдельным выработкам. Знание этих изменений даёт возможность корректировать режимы работы источников тяги и вентиляционных устройств, обеспечивая подачу нормативного количества свежего воздуха на каждый из участков рудника [24].

Линейные сопротивления горных выработок определяются однозначно их типом и геометрическими размерами [18], однако на практике значительный вклад в потери давления вносят местные сопротивления, теоретическое определение которых, как правило, не представляется возможным. К их числу относятся, прежде всего, уменьшение или увеличение сечения выработок, вызванные наличием зон обрушения породы, горного оборудования и вентиляционных перемычек, а также, в меньшей степени, изгибами и сопряжениями выработок [25-27]. Поэтому регулярные плановые воздушно-депрессионные съёмки (ВДС) являются актуальными мероприятиями для получения достоверной информации о текущем аэродинамическом состоянии рудничной сети.

Проведение ВДС предполагает измерение расходов воздуха $Q_{j}, \mathrm{M}^{3} / \mathrm{c}$ и падений давления (напора, депрессии) $\Delta P_{j}$, Па во всех выработках рудника, по результатам которого определяются их аэродинамические сопротивления $R_{j}=\left|\Delta P_{j} / Q_{j}^{2}\right|$, кг/м ${ }^{7}$. Для определения всех сопротивлений сети, состоящей из $n$ ветвей (выработок), необходимо знание $2 n$ величин: $n$ значений расходов воздуха и $n$ значений падений давления на каждой выработке. С учётом того, что граф сети связан первым и вторым законами сетей, отражающих законы сохранения массового расхода воздуха и энергии, количество необходимых замеров может быть уменьшено в 2 раза: с $2 n$ до $n$.

Сохранение массы воздуха постоянной плотности для рудничной сети, состоящей из $n$ ветвей и $k$ узлов, задаётся $k$ 1 уравнениями:

$$
0=\sum_{j} Q_{j}^{(i)},
$$

где $i$ - номер узла (от 1 до $k-1$ ), $j$ - номера выработок, инцидентных узлу с номером $i$. Поскольку общее число уравнений должно быть равно числу неизвестных $n$, 
то оставшееся число уравнений в количестве $m=n-(k-1)$ отвечает за сохранение энергии при движении воздуха по замкнутым контурам:

$$
\sum_{j} \Delta \pi_{j}^{(s)}=\sum_{j} \Delta P_{j}^{(s)}=\sum_{j}\left( \pm R_{j}^{(s)}\right) Q_{j}^{(s)}\left|Q_{j}^{(s)}\right|,(12
$$

где $s$ - номер (от 1 до $m$ ) уравнения (независимого контура), $j$ - номера выработок, содержащихся в контуре с номером $s$, $\Delta \pi_{j}^{(s)}$, Па - напор источника тяги в выработке с номером $j$ контура с номером $s$, $\Delta P_{j}^{(s)}$, Па - падение напора в выработке с номером $j$ контура с номером s.

При известных значениях аэродинамических сопротивлений всех выработок и источников тяги система уравнений (11) - (12) однозначно определяет все расходы воздуха, поскольку решаются $n$ независимых уравнений для $n$ неизвестных величин [28].

Однако обратная задача оказывается математически некорректной, т.к. при заданных напорах источников тяги и расходах воздуха определить однозначно сопротивления ветвей невозможно [29]. Действительно, при задании всех расходов уравнения (11) принимают вид тождественных равенств или неравенств, в случае несоблюдения нулевого баланса в узлах, а оставшееся количество $m$ контурных уравнений (12) оказывается недостаточным для определения $n$ неизвестных сопротивлений. Причина такой некорректности в том, что нельзя задавать $n$ расходов, поскольку только $m$ из них независимы, т.к. есть $k-1$ уравнений (11), их связывающих, а $n-(k-1)=m$.

Таким образом, задание $m$ расходов однозначно определяет все остальные $k-1$. В оставшихся $m$ уравнениях (12) есть $n$ неизвестных сопротивлений, значит, $n-m$ из них должны быть заданы, т.е. должны быть известны $n-m$ перепадов давлений, которые и являются необходимыми для решения обратной задачи данными. Из вышеизложенного следует, что минимальное количество замеров ВДС для определения аэродинамических сопротивлений всех $n$ выработок рудничной сети равно $n$, причём из них должно быть $m$ замеров расходов и $n-m$ замеров перепадов давлений.

В практике проведения ВДС бывает как избыток, так и дефицит замеренных данных. И если в первом случае избыточные данные исключаются по критерию наименьшей достоверности, то во втором случае они должны быть как-то дополнены. В основу способа такого дополнения, предложенного в [30], заложен принцип минимизации суммарных отклонений значений сопротивлений выработок от их проектных значений, определяемых по типам и геометрическим размерам. В случае отсутствия экспериментальных данных такой подход представляется наиболее рациональным для их получения и дальнейшего использования в расчётах.

Разработанный метод выбора множеств ветвей рудничной сети, независимых по расходам воздуха и падениям давления, реализованный численно в виде интерактивного расчётного модуля, позволил минимизировать затраты труда и времени при проведении воздушно-депрессионных съёмок и обработке их результатов, а также увеличить точность определения аэродинамических сопротивлений горных выработок.

\section{Заключение}

Разработанные модели интегрированы в программной среде «АэроСеть» [31], в комплексе являются универсальным инструментом для моделирования предполагаемых аварийных нарушений рудничного проветривания, а также способов их профилактики и устранения. Программное приложение позволяет разрабатывать подробные схемы планов мероприятий по ликвидации и локализации последствий аварий (ПМЛЛПА), используемых во время возникновения чрезвычайных ситуаций для спасения работающих в руднике людей (рис. 7). Реализованные вычислительные методы предоставляют возможность специалистам рудника и ВГСЧ проводить инженерные расчеты, прорисовывать маршруты движения отделений и определять их протяжен- 


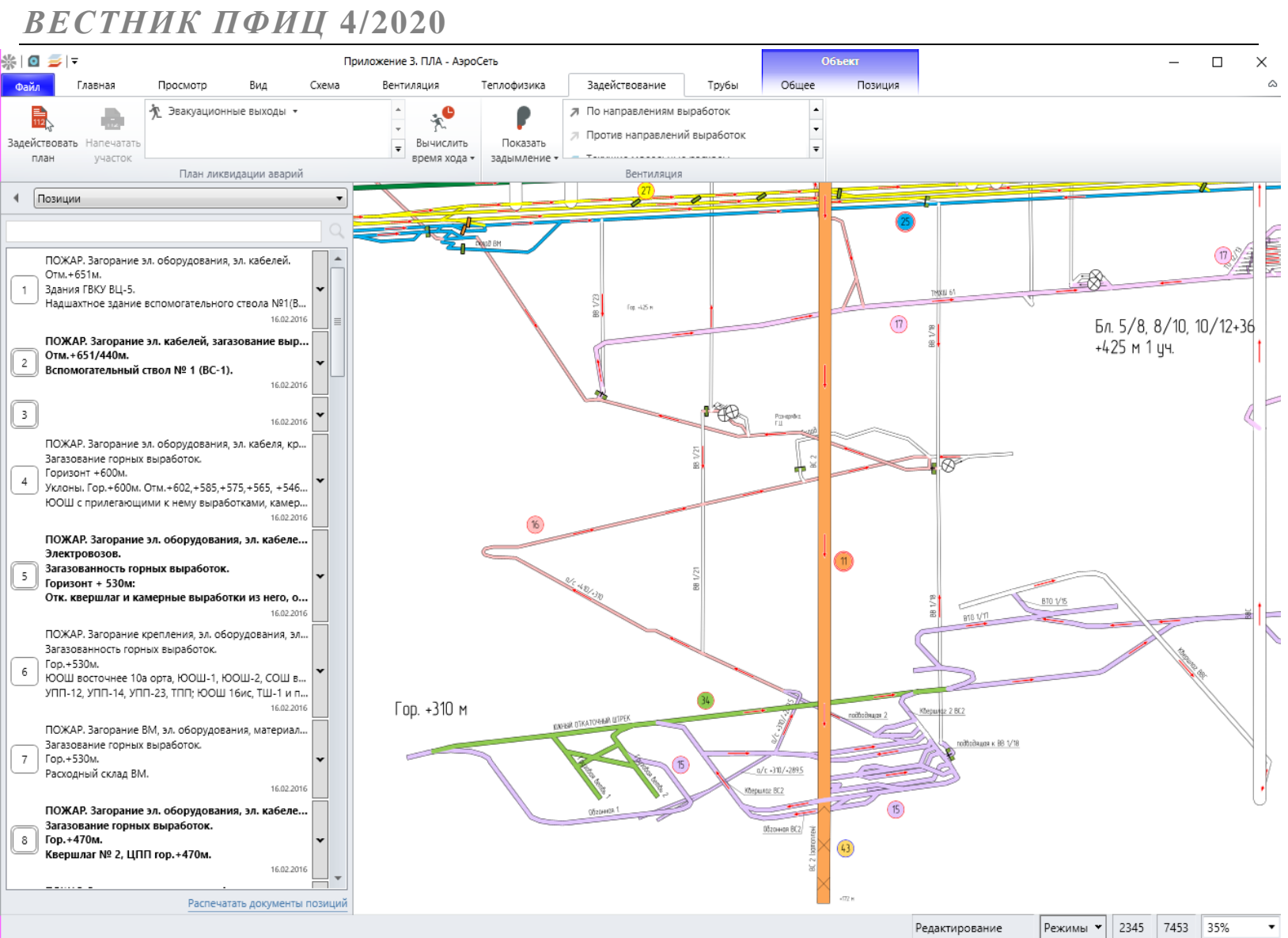

Рис. 7. Графическая часть ПМЛЛПА Расвумчоррского рудника АО «Апатит»

ность, что делает программу мощным способствующим увеличению скорости аналитическим аппаратом поддержки принятия решений и исключению в условиях чрезвычайных ситуаций, влияния человеческого фактора.

\section{Библиографический список}

1. Красноштейн А.Е., Казаков Б.П., Шалимов А.В. Численное моделирование нестационарных процессов распространения газовых примесей по выработкам рудника в условиях рециркуляционного проветривания // Физико-технические проблемы разработки полезных ископаемых. - 2006. - № 1. - С. 95-101.

2. Казаков Б.П., Шалимов А.В., Гришин Е.Л. Теплообмен вентиляционного воздуха с крепью воздухоподающего ствола и породным массивом // Физико-технические проблемы разработки полезных ископаемых. - 2011. - № 5. - С. 91-99.

3. Воропаев А.Ф. Теория теплообмена рудничного воздуха и горных пород в глубоких шахтах. - М.: Недра, 1966. - 250 c.

4. Кошель А.В., Исаевич А.Г. Оценка возможности применения нагнетательного способа проветривания на калийных рудниках // Актуальные проблемы повышения эффективности и безопасности эксплуатации горношахтного и нефтепромыслового оборудования. - 2016. - № 1. - С. 218 - 223.

5. Шалимов А.В. Численное моделирование газовоздушных потоков в экстремальных ситуациях и аварийных режимов проветривания рудников и шахт // Физико-технические проблемы разработки полезных ископаемых. - 2011. - № 6. - С. $84-92$.

6. Меренков А.П., Хасилев М.Ю. Теория гидравлических цепей. - Москва, 1985. - С. 279.

7. Казаков Б.П., Шалимов А.В. Сравнительный анализ методов расчёта воздухораспределения в рудничных вентиляционных сетях // Горное эхо / Вестник Горного института УрО РАН. - 2009. № 1 (35). - C. 17-20.

8. Шалимов А.В. Адаптация метода узловых давлений к расчётам воздухораспределения в рудничных вентиляционных сетях // Известия Тульского государственного университета. Науки о Земле. 2011. - № 1. - C. 95-101.

9. Cross $H$. Analysis of flow in networks of conduits or conductors // Engineering Experiment Station, University of Illinois. - 1936. - P. 38. 
10. Todini E.A., Plati S. Gradient method for the analysis of pipe networks // International Conference on Computer Applications for Water Supply and Distribution, Leicester Polytechnic, UK, September 8-10. - 1987.

11. Амосов А.А., Дубинский Ю.А., Копченова Н.В. Вычислительные методы для инженеров. - М.: Высшая школа. - 1994. - 544 с.

12. Круглов Ю.В., Левин Л.Ю., Зайщев А.В. Моделирование переходных процессов в вентиляционных сетях подземных рудников // Физико-технические проблемы разработки полезных ископаемых. 2011. - № 5. - C. $100-108$.

13. Patankar S.V. Numerical heat transfer and fluid flow // Taylor and Francis. - 1981. - P. 196.

14. Постникова М.Ю. Влияние выработанных пространств на вентиляцию рудников в переходный период аварийной вентиляции // Горный информационно-аналитический бюллетень (научнотехнический журнал). - 2011. - № 3. - С. 206 - 209.

15. Wang S., Liu B., Liu S. Computer Simulation of Unsteady Airflow Processes in Mine Venilation Networks // Journal of liaoning technical university (natural science edition). - 2000. - P. $21-29$.

16. Лискова М.Ю. Влияние выработанных пространств на воздухораспределение при включении ГВУ после ее длительной остановки // Известия Тульского государственного университета. Науки о Земле. - 2013. - № 2 - С. 51 - 56.

17. Казаков Б.П., Шалимов А.В., Гришин Е.Л. Моделирование нестационарных процессов движения воздуха и переноса тепла и примесей по выработкам рудничных вентиляционных сетей в программном комплексе АэроСеть // Известия Тульского государственного университета. Науки о Земле. - 2010. - № 2. - С. 64-68.

18. Мохирев Н.Н., Радько В.В. Инженерные расчёты вентиляции шахт. Строительство. Реконструкция. Эксплуатация. - М.: Недра, 2007. - 325 с.

19. Идельчик И.Е. Справочник по гидравлическим сопротивлениям - М.: Машиностроение. $1992 .-672$ с.

20. Казаков Б.П., Шалимов А.В., Стукалов В.А. Моделирование аэродинамических сопротивлений сопряжений горных выработок // Горный журнал. - 2009. - №12. - С. 56-58.

21. Карпов А.М., Фролов М.А., Чухонщев Н.Ф. Анализ случая работы «вентиляторов-толкачей» в шахтной вентиляционной сети // Уголь. - 1955. - № 11. - С. 9 - 10.

22. Дейли Дж, Харлеман Д. Механика жидкости. - М.: Энергия, 1971. - 480 с.

23. Гримитлин М.И. Вентиляция и отопление цехов судостроительных заводов. - Л., 1978. -240 с.

24. Об утверждении Федеральных норм и правил в области промышленной безопасности «Правила безопасности при ведении горных работ и переработке твердых полезных ископаемых» // Федеральная служба по экологическому, технологическому и атомному надзору. - Приказ от 11 декабря 2013 года № 599. - 195 с.

25. Левин Л.Ю., Семин М.А., Газизуллин Р.Р. Разработка метода расчета местных аэродинамических сопротивлений при решении сетевых задач воздухораспределения // Горный информационноаналитический бюллетень (научно-технический журнал). - 2014. - №9. - С. 200-205.

26. Харев А.А. Местные сопротивления шахтных вентиляционных сетей. - М.: Углетехиздат. - 1954. - 248 с.

27. Казаков Б.П., Мальщев С.В., Семин М.А. Обоснование участков измерения аэродинамических параметров воздушного потока при определении аэродинамического сопротивления стволов // Горный информационно-аналитический бюллетень (научно-технический журнал). - 2015. - №5. - С.-75.

28. Maleki B., Mozaffari E.A. Comparative Study of the Iterative Numerical Methods Used in Mine Ventilation Networks // International Journal of Advanced Computer Science and Applications. - 2016. Vol. 7. - № 6. - P. $21-28$.

29. Öktem O., Adler J. Solving ill-posed inverse problems using iterative deep neural networks // Inverse Problems. - 2017. -24 p.

30. Казаков Б.П., Исаевич А.Г., Мальцев С.В., Семин М.А. Автоматизированная обработка данных воздушно-депрессионной съемки для построения корректной математической модели вентиляционной сети рудников // Известия высших учебных заведений / Горный журнал. - 2016. - № 1. С. 22-30.

31. Свидетельство об официальной регистрации программы для ЭВМ №2015610589 Аналитический комплекс «АэроСеть» // Мальков П.С., Зайщев А.В., Кашников А.В., Кормщиков Д.С., Круглов Ю.В., Левин Л.Ю., Казаков Б.П., Шалимов А.В. / Федеральная служба по интеллектуальной собственности, зарегистрировано в Реестре программ для ЭВМ 14 января 2015 года. 


\title{
METHODS OF FORECASTING, PREVENTION AND RESPONSE TO ACCIDENTAL VIOLATIONS IN MINE VENTILATION
}

\author{
Kazakov B.P., Shalimov A.V., Grishin E.L., Zaitsev A.V., \\ Isaevich A.G., Kormshchikov D.S.
}

Mining Institute UB RAS

Studies of aero and heat-gas-dynamic processes occurring in emergency modes of ventilation, in particular during mine fires, are the basis for the development of a set of measures aimed at preventing accidents, as well as the management of emergency ventilation in real time. The description of the processes of heat and smoke transfer in the mine workings is carried out on the basis of thermal-mechanical calculation, which is based on a mathematical model of conjugate unsteady heat transfer. Modeling of non-stationary air distribution under the influence of variable thermal depressions is carried out on the basis of a modified method of contour flow, taking into account the inertia of air flows and mechanical compressibility of air in the mine worked-out spaces. To assess the stability of emergency ventilation of the mine in case of disconnection of the traction source, a model of convective stratification of air flows along the cross section of mine workings was developed. Based on the laws of conservation of energy and momentum, universal mathematical relationships were derived to determine the loss of depression on the interfaces of mine workings of any configuration, with the help of which studies of reversible ventilation modes were carried out. The analysis of the efficiency of ventilation of working areas of mines with large cross-section due to the use of recirculation systems with ejection sources of thrust is done. A method has been developed for interactive work with data in the preparation and processing the results of air - depression surveys of ventilation networks of mines, which allows determining the aerodynamic resistance of all workings in conditions of missing or redundant conflicting data. On the basis of comprehensive accounting of the upper-air and thermophysical factors that determine the parameters of the mine atmosphere, the air flow control system has been developed in emergency ventilation modes using adjustable traction sources and ventilation doors. All models are implemented numerically and integrated into a single software package designed to solve complex network upper-air problem of forecasting, prevention and control of mine accidents.

Keywords: heat, fire, air distribution, open goaf, natural draft, convective stratification of airflows, conjunction of airways, booster fans, ventilation survey.

\section{Сведения об авторах}

Казаков Борис Петрович, доктор технических наук, профессор, главный научный сотрудник отдела аэрологии и теплофизики, Горный институт УрО РАН - филиал Пермского федерального исследовательского центра УрО РАН (ГИ УрО РАН), 614007, г. Пермь, ул. Сибирская, 78A; e-mail: aero_kaz@mail.ru

Шалимов Андрей Владимирович, доктор технических наук, ведущий научный сотрудник отдела аэрологии и теплофизики, ГИ УрО РАН; e-mail: shalimovav@mail.ru

Гришин Евгений Леонидович, кандидат технических наук, заведующий сектором аэрологической безопасности и горноспасательного дела отдела аэрологии и теплофизики, ГИ УрО РАН; e-mail: aeroevg@mail.ru

Зайцев Артем Вячеславович, кандидат технических наук, заведующий сектором математического моделирования и информационных технологий отдела аэрологии и теплофизики, ГИ УрО РАН; е-mail:

Исаевич Алексей Геннадьевич, кандидат технических наук, заведующий сектором рудничной вентиляции и горной теплофизики отдела аэрологии и теплофизики, ГИ УрО РАН; e-mail: aero_alex@mail.ru

Кормщиков Денис Сергеевич, кандидат технических наук, научный сотрудник отдела аэрологии и теплофизики, ГИ УрО РАН; e-mail: voroninaao@gmail.com 